\title{
SOBERANIA, DISCIPLINA E SEGURANÇA: UMA ANÁLISE DO DISPOSITIVO E SUAS POSSÍVEIS VERTENTES EM MICHEL FOUCAULT
}

\author{
SOVEREIGNTY, DISCIPLINE AND SECURITY: AN ANALYSIS OF THE DEVICE AND ITS POSSIBLE \\ STRANDS IN MICHEL FOUCAULT
}

Daniel Luis Cidade Gonçalves*

\begin{abstract}
RESUMO
O objetivo deste trabalho consiste em, partindo do conceito de dispositivo em Michel Foucault, traçar uma análise sob a perspectiva das relações de saber/poder em busca de uma compreensão mais detalhada daquilo que poderíamos chamar de dispositivo de soberania, dispositivo disciplinar e dispositivo de segurança. Trata-se de investigar a interdependência presente nos discursos que legitimam cada dispositivo e as relações de poder que permitem as inúmeras articulações práticas que encontramos em nossas sociedades. A partir dessa metodologia de análise do poder, investigaremos a concepção jurídico-discursiva de poder, o conceito de poder disciplinar, assim como aquilo que Foucault chama de biopolítica. Com isso, fica mais acessível a compreensão do mundo contemporâneo globalizado como um momento em que inúmeros dispositivos entram em choque, tornando as análises políticas possíveis cada vez mais complexas. Buscamos um diagnóstico do presente, através da compreensão de suas disposições atuais de poder, para que com isso possamos seguir em frente em busca de relações mais livres e menos opressivas, normalizadas ou regulamentadas. PALAVRAS-CHAVE: Dispositivo. Soberania. Disciplina. Segurança. Poder.
\end{abstract}

\section{ABSTRATCT}

The objective of this work is to draw from the concept of device in Michel Foucault an analysis from the perspective of the relations of knowledge/power in search of a more detailed understanding of what we could call a device of sovereignty, disciplinary device and device of security. It is a question of investigating the interdependence present in the discourses that legitimize each device and the relations of power that allows the innumerable practical articulations that we find in our societies. From this methodology of analysis of the power, we will investigate the legal-discursive conception of power, the concept of disciplinary power, as well as what Foucault calls biopolitics. As a result, the understanding of the globalized contemporary world becomes more accessible as a time when numerous devices come into shock, making the possible political analysis more and more complex. We seek a diagnosis of the present, by understanding its present dispositions of power, so that we can move forward in search of freer and less oppressive, normalized or regulated relations.

KEY-WORDS: Device. Sovereignty. Discipline. Security. Power.

\footnotetext{
* Mestre e doutor em Filosofia Política e Ética pela Universidade Federal de Santa Catarina. Professor substituto na Fundação Universidade Regional de Blumenau. E-mail: daniel.cidade@ gmail.com.
} 


\section{DISCURSOS E DISPOSITIVOS}

Para compreendermos os conceitos de discurso e dispositivo em Foucault, precisamos antes de tudo colocar em cheque aquilo que o autor chama de "estatuto do sujeito". Aqui Foucault se refere a um estatuto antropológico que tem como objetivo colocar o sujeito como um ser autônomo e epistemologicamente privilegiado. Um conhecedor do mundo que usa sua liberdade (ou seu livre-arbítrio) para perpetuar mudanças que estão ao alcance de seu conhecimento. Segundo Johanna Oksala (2005, p. 1, tradução nossa), para Foucault o sujeito "não é o agente das mudanças sociais ou epistêmicas, mas o efeito delas. Não existe sujeito em si anterior à codificação cultural normalizadora que transforma os seres humanos em sujeitos." Neste contexto, cabe ressaltar que Foucault admite que seu interesse pela questão do poder é diretamente condicionado ao seu interesse pela questão do sujeito:

\footnotetext{
Meu papel - mas este é um termo muito pomposo - é mostrar às pessoas que elas são muito mais livres do que pensam, que elas tomam por verdadeiros, por evidentes certos temas fabricados em um momento particular da história, e que essa pretensa evidência pode ser criticada e destruída. O papel de um intelectual é mudar alguma coisa no pensamento das pessoas. (FOUCAULT, 2006, p. 288).
}

Com Paul Veyne (2014, p. 25), historiador que manteve uma profunda amizade com Foucault, o sujeito de conhecimento não é soberano: "cada um só pode pensar como se pensa em seu tempo", referindo-se a uma frase proferida por Jean d'Ormesson. Compreender o que é um discurso é tentar entender como as práticas sociais podem constituir formações discursivas que, por sua vez, influenciam na formação das subjetividades de diferentes indivíduos. Metaforicamente, Veyne alega que seria como se nossos discursos fossem aquários cuja existência ignoramos. É verdade que os discursos variam ao longo do tempo, mas também é verdade que eles passam por verdadeiros, às vezes de maneira completamente inconteste. Judith Revel nos fornece uma boa definição de discurso:

O discurso geralmente designa, na obra de Foucault, um conjunto de enunciados que podem pertencer a campos diferentes, mas que obedecem, apesar de tudo, a regras de funcionamento comuns. Essas regras não são apenas linguísticas ou formais, mas reproduzem uma série de divisões historicamente determinadas (por exemplo, a grande divisão razão/desrazão): a "ordem do discurso" própria de um período particular possui, portanto, uma função normativa e reguladora e estabelece

\footnotetext{
1 "It is not the agent of social or epistemic changes, but rather the effect of them. There is no subject in itself prior to the normalizing cultural coding that turns the human being into a subject".
} 
Artigo: Soberania, disciplina e segurança: uma análise do dispositivo e suas possíveis vertentes em Michel Foucault

mecanismos de organização do real por meio da produção de saberes, de estratégias e de práticas. (REVEL, 2011, p. 41).

O conceito de discurso, todavia, é um pouco limitado. Sem abandoná-lo, utilizaremos um conceito mais abrangente, que nos permite um instrumental analítico mais consistente. Trata-se do conceito de dispositivo que, em Foucault, possui caráter heterogêneo. Nas palavras do autor:

\begin{abstract}
Através deste termo [dispositivo] tento demarcar, em primeiro lugar, um conjunto decididamente heterogêneo que engloba discursos, instituições, organizações arquitetônicas, decisões regulamentares, leis, medidas administrativas, enunciados científicos, proposições filosóficas, morais, filantrópicas. Em suma: o dito e o não dito são os elementos do dispositivo. O dispositivo é a rede que se pode estabelecer entre estes elementos. (FOUCAULT, 1979, p. 244).
\end{abstract}

Existe, dessa forma, uma relação direta entre os discursos e os dispositivos. Primeiramente, é importante ressaltar que o conceito de dispositivo engloba o de discurso e tenta ir além. Se o discurso se refere às verdades ditas em uma determinada época, que obedecem a uma série de regras (fazem parte do aquário conceitual presente naquele momento), o dispositivo também diz respeito ao não dito, aquilo que está presente nas práticas sociais, mas muitas vezes de maneira inconsciente, sem que seja necessário qualquer tipo de tradução linguística.

Nós, enquanto sujeitos, não somos soberanos porque nos encontramos sujeitados aos discursos e dispositivos presentes no contexto em que formamos nossa subjetividade. Isso não nos faz meros frutos de dispositivos, tampouco nega completamente nossa liberdade, embora torne-a um conceito a ser revisitado e reformulado sob essa nova perspectiva. Segundo Veyne (2014, p. 25) "quando desabam a escravidão e todo o dispositivo legal e mental que a sustenta, desaba também sua "verdade"”. Dessa forma, não somos contra a escravidão por sermos mais humanos ou termos um caráter ou uma natureza superior à dos nossos antepassados, mas porque fomos constituídos a partir de discursos e dispositivos incompatíveis com sua existência (ou, no mínimo, muito menos compatíveis).

Podemos falar, com Foucault, que existe um jogo entre o discursivo e o não discursivo. Este jogo, por sua vez, está diretamente relacionado com aquilo que chamaremos de "interdependência entre o saber e o poder", que consiste basicamente na ideia de que "não há relação de poder sem constituição correlata de um campo de saber, nem saber que não suponha e não constitua ao mesmo tempo relações de poder" (FOUCAULT, 1987, p. 26-27). 
Diferentemente de nossa tradição platônica, na qual o saber só pode existir quando as relações de poder estiverem todas suspensas, Foucault acredita que essa pretensão possui um caráter ilusório. Na realidade, o poder é um elemento sempre presente quando estamos constituindo algum campo de conhecimento ou institucionalizando algum tipo de verdade, assim como o saber é necessário para legitimar e tornar possível inúmeras relações de poder.

O conceito de dispositivo, nesse contexto, tem o objetivo de englobar este conjunto de proposições que se referem aos discursos e as relações de saber/poder, responsáveis pela constituição de inúmeros tipos de sujeito. A partir dos dispositivos, podemos entender melhor nossas formatações sociais; todo aparato presente (discursivamente ou não) nas inúmeras relações de saber/poder/subjetividade. Analisando os dispositivos que se formam, podemos compreender melhor a condição em que nos encontramos.

\section{DISPOSITIVO DE SOBERANIA: A CONCEPÇÃO JURÍDICO-DISCURSIVA DO PODER}

Em primeiro lugar, precisamos compreender aquilo que o autor chama de "concepção jurídico-discursiva do poder", presente nos dispositivos de soberania. De certa forma, essa concepção se refere ao senso comum, ao modo como entendemos o poder no cotidiano. $\mathrm{O}$ poder, sob essa perspectiva, é visto como uma propriedade daquele que o detém e cuja legitimidade precisa ser justificada. Em suas análises sobre o poder (ou melhor, sobre as relações de poder), Foucault busca se desvencilhar dessa concepção.

$\mathrm{Na}$ concepção jurídico-discursiva (que também pode ser chamada de "poder soberano"), encontramos a "relação negativa", na qual o poder é entendido como aquilo que proíbe e interdita uma ação. Temos também a "instância da regra", na qual o poder é aquilo que dita a lei e reduz seu objeto a um campo binário que só fala a linguagem do permitido e proibido. Ainda, temos o "ciclo da interdição" na qual o poder se utiliza da lógica da censura para exercer três funções principais: "afirmar que não é permitido, impedir que se diga, negar que exista" (FOUCAULT, 1988, p. 82). Em último lugar, na "unidade do dispositivo", encontramos uma concepção de poder na qual ele supostamente se exerceria igualmente em todos os níveis, sustentado por uma forma geral que toma a forma do direito e joga o jogo do lícito e ilícito, da transgressão e do castigo.

Importante ressaltar que, para Foucault, a lógica jurídico-discursiva é bastante limitada. "Em face de um poder, que é lei, o sujeito que é constituído como sujeito - que é 
Artigo: Soberania, disciplina e segurança: uma análise do dispositivo e suas possíveis vertentes em Michel Foucault

'sujeitado' - é aquele que obedece.” (FOUCAULT, 1988, p. 82). Compreender esta limitação nos ajuda a entender melhor o dispositivo de soberania. A concepção jurídico-discursiva tem como paradigma clássico o governo monárquico, embora esteja bastante presente nas lógicas democráticas. Seu elemento mais importante é a lei, seu principal ator é o soberano. Em termos de poder, a lei se refere a qualquer elemento dentro de um dispositivo que conseguiu se institucionalizar como interdito legítimo a todos aqueles que se encontram sob o seu jugo. A lei proíbe os súditos de agirem de tal maneira. Descumpri-la é ilegítimo, seja ela justa ou não. O soberano, por sua vez, é aquele que possui o poder último sobre um território sob o qual reside um conjunto de súditos. Embora no modelo monárquico o soberano seja um indivíduo, ele pode ser também um corpo de cidadãos. A filosofia política moderna se preocupou bastante em encontrar a legitimidade da lei e da soberania. Quais seriam os elementos que garantem legitimidade e fazem como que uma lei e uma pretensa soberania deixem de ser um conjunto arbitrário de ordens?

Foucault, contudo, não joga esse jogo. Pelo contrário, o filósofo francês se questiona por que aceitamos tão facilmente essa lógica em uma sociedade na qual os aparelhos de poder são tão inventivos, sutis e delicados? A resposta do autor consiste na ideia de que para tolerar o poder é preciso mascará-lo. "O poder seria aceito se fosse inteiramente cínico?" (FOUCAULT, 1988, p. 83). A forma geral de sua aceitabilidade consiste em compreendê-lo como limite traçado a nossa liberdade. Isso significa que aceitamos que a vida em sociedade é complicada, e para garantir a harmonia social leis são necessárias. Mas será apenas isso que os dispositivos de poder fazem? Será que a harmonia consiste no único objetivo de nossos soberanos e nas únicas restrições visadas por nossas leis?

Foucault alega metaforicamente que precisamos "cortar a cabeça do rei". A filosofia política atual dá muita importância a uma leitura frequentemente engessada na lógica jurídicodiscursiva, dando demasiada importância ao direito, à lei, ao Estado e à soberania. Para seguirmos adiante, libertos deste modelo, precisamos buscar uma concepção de poder que nos permita pensar "o sexo sem lei e o poder sem rei” (FOUCAULT, 1988, p. 87). Esse jogo de palavras (que soa igualmente bem em francês), tem o intuito de deslocar às análises tradicionais do poder, excessivamente preocupadas com o permitido e o proibido, assim como com a legitimidade e a ilegitimidade do poder. Nas palavras do autor:

Parece-me que se deve compreender o poder, primeiro, como a multiplicidade de correlações de forças imanentes ao domínio onde se exercem e constitutivas de sua organização; o jogo que através de lutas e afrontamentos incessantes as transforma, 
reforça, inverte; os apoios que tais correlações de força encontram umas nas outras, formando cadeias ou sistemas ou ao contrário, as defasagens e contradições que as isolam entre si; enfim, as estratégias em que se originam e cujo esboço geral ou cristalização institucional toma corpo nos aparelhos estatais, na formulação da lei, nas hegemonias sociais. A condição de possibilidade do poder, em todo caso, o ponto de vista que permite tornar seu exercício inteligível até em seus efeitos mais "periféricos" e, também, enseja empregar seus mecanismos como chave de inteligibilidade do campo social, não deve ser procurada na existência primeira de um ponto central, num foco único de soberania de onde partiriam formas derivadas e descendentes; é o suporte móvel das correlações de força que, devido a sua desigualdade, induzem continuamente estados de poder, mas sempre localizados e instáveis. Onipresença do poder: não porque tenha o privilégio de agrupar tudo sob sua invencível unidade, mas porque se produz a cada instante, em todos os pontos, ou melhor, em toda relação entre um ponto e outro. O poder está em toda parte; não porque englobe tudo e sim porque provém de todos os lugares. (FOUCAULT, 1988, p. 88-89).

Fica claro então que Foucault desenvolve aquilo que irá chamar de uma "analítica do poder" como uma maneira de superar a noção de poder soberano. Entender o poder como uma multiplicidade de correlação de forças implica aceitar a interdependência das relações de poder e saber e ir um pouco mais além, reconhecendo que inúmeras forças correlacionadas (detectáveis ou não) são capazes de constituir discursos e dispositivos específicos que atuam de determinada maneira, influenciando diretamente a vida dos sujeitos que, perante tais forças, encontram-se na qualidade tanto de sujeitos quanto de sujeitados. Aquilo que possibilita a existência de uma relação de poder e torna inteligível algum discurso presente no campo social nunca pertence apenas a uma instância centralizada cujas forças derivam de um único núcleo. Tampouco encontraremos algum tipo de legitimidade trans-histórica para além dos discursos e dispositivos que surgem e tornam as relações de saber/poder aceitáveis e até mesmo desejáveis.

A despeito dessa tentativa de superar o modelo jurídico-discursiva, nos cabe ressaltar que é demasiado importante a sua compreensão. Não é nem um pouco anacrônico pressupor que embora Foucault nos dê ferramentas mais acuradas para analisar o poder, a concepção jurídico-discursiva de poder ainda impera em nosso imaginário social. Não superamos aquilo que podemos chamar de "dispositivo de soberania", ou seja, um dispositivo no qual as relações heterogêneas que o constituem são criadas e legitimadas sob a ótica jurídicodiscursiva. O modelo do direito, da soberania e da lei, que busca a legitimidade do poder e o soberano legítimo que o possui como uma propriedade, ainda são bastante úteis, se não para explicar, ao menos para entender inúmeras relações sociais vigentes.

Cabe ainda ressaltar que, em Vigiar e punir, antes de abordar a prisão como forma generalizada de punição presente nas sociedades modernas, Foucault analisa a punição através 
Artigo: Soberania, disciplina e segurança: uma análise do dispositivo e suas possíveis vertentes em Michel Foucault

do suplício, presente especialmente nas sociedades monárquicas nas quais a concepção jurídico-discursiva era predominante. Foucault narra o suplício de maneira atroz: "seu corpo será puxado e desmembrado por quatro cavalos e seus membros e corpo consumidos ao fogo, reduzidos a cinzas, e suas cinzas lançadas ao vento" (FOUCAULT, 1987, p. 9). Trata-se de uma pena corporal dolorosa que, além de hierarquizar, faz parte de um ritual de ostentação da infâmia do infrator em que o triunfo do poder soberano deve ficar claro e exposto. De fato, o seu principal objetivo era justamente a reativação desse poder soberano, na medida em que qualquer crime devia ser entendido como um ataque direto a ele. Desrespeitar a força da lei implica desrespeitar a soberania vigente. O suplício é uma réplica direta a essa ofensa, cujo objetivo não é restaurar a justiça, mas reativar o poder.

O suplício eventualmente desapareceu. Todavia, para Foucault, isso não se deve ao fato de que nos tornamos mais humanos e deixamos de considerar admissíveis tamanhas atrocidades. Trata-se, antes de tudo, do momento em que o corpo deixa de ser o principal alvo da repressão penal. Temos uma mudança na tecnologia do poder em que podemos vislumbrar a transição do poder soberano àquilo que podemos chamar de "poder disciplinar". O dispositivo de soberania deixa de ser tão presente, dando lugar ao dispositivo disciplinar. O corpo perde sua centralidade dando espaço para a "alma" dos indivíduos como principal alvo de punição.

\section{DISPOSITIVO DISCIPLINAR: A NORMALIZAÇÃO DOS INDIVÍDUOS}

Em Vigiar e punir, com o desaparecimento dos suplícios e antes da completa difusão da prisão como modelo universal de punição, Foucault constata o surgimento, mais teórico do que prático, de um período de transição entre os discursos punitivos. Segundo o filósofo francês, a partir do século XVIII, quando os suplícios começam a se tornar intoleráveis, surgem reformistas para sugerir que as punições devam ser moderadas e proporcionais aos delitos cometidos. "A duração da pena só tem sentido em relação a uma possível correção, e a uma utilização econômica dos criminosos corrigidos." (FOUCAULT, 1987, p. 101). Foucault ressalta que o que impulsiona tais modificações se refere tanto a mudanças na tecnologia de poder envolvida quanto na lógica punitiva. A punição não se dá mais em nome da reativação do poder soberano, mas em defesa da sociedade. Não é tanto o sofrimento do criminoso que precisa ser respeitado, mas o dos juízes e expectadores que podem ter seus corações 
endurecidos. Trata-se de um controle necessário dos efeitos de poder presentes no momento punitivo.

A pena deveria ter a função de evitar que o crime seja cometido novamente, fazendo com que o foco deixe de ser uma ofensa passada e passa a ser uma ofensa futura. Busca-se a punição ideal que elimine completamente a atração de um delito. Os reformadores sugerem uma série de penas naturais e análogas ao próprio crime. Os que abusam da liberdade serão privados da sua, os que abusam dos privilégios das funções públicas terão seus direitos civis cassados, o roubo será punido com o confisco, e o assassinato com a morte. A prisão como forma geral de punição nunca é apresentada nessas propostas (apenas como uma das punições possíveis). Foucault ressalta, todavia, que essa reforma fracassou completamente e quase que imediatamente, sendo substituída em menos de vinte anos pela prisão.

É nos perguntando, junto com Foucault, o que tornou possível que a prisão tenha se transformado em uma das formas mais gerais dos castigos legais, que podemos entender sua análise do poder disciplinar. Para Foucault, a prisão permite a formação de um sistema punitivo capaz de produzir um saber individualizante cuja base não tem como referência um crime cometido mas a virtualidade de perigos presentes em um indivíduo. Não se trata de apagar um crime, mas transformar um culpado. O tipo de sujeito visado por essa tecnologia de poder, segundo Foucault, é o sujeito obediente.

E finalmente, o que se procura reconstruir nessa técnica de correção não é tanto o sujeito de direito, que se encontra preso nos interesses fundamentais do pacto social: é o sujeito obediente, o indivíduo sujeito a hábitos, regras, ordens, uma autoridade que se exerce continuamente sobre ele e em torno dele, e que ele deve deixar funcionar automaticamente nele. Duas maneiras, portanto, bem distintas de reagir à infração: reconstituir o sujeito jurídico do pacto social - ou formar um sujeito de obediência dobrado à forma ao mesmo tempo geral e meticulosa de um poder qualquer. (FOUCAULT, 1987, p. 106).

É nesse contexto de generalização da prisão como forma punitiva de uma sociedade que podemos entender o contexto disciplinar analisado pelo autor. Embora não seja a primeira vez que o corpo seja utilizado punitivamente, é somente no contexto disciplinar que surge a ideia de trabalhar o corpo detalhadamente, exercendo uma coecção sem folga, visando a colocá-lo em um nível mecânico que permita o seu controle minucioso e lhe imponha uma relação de docilidade-utilidade, sujeitando completamente suas forças. Foucault dá o nome de Disciplina para essa fórmula geral de dominação (que vai muito além da mera existência de processos disciplinares presentes em outros lugares). 
Artigo: Soberania, disciplina e segurança: uma análise do dispositivo e suas possíveis vertentes em Michel Foucault

\begin{abstract}
A disciplina fabrica assim corpos submissos e exercitados, corpos "dóceis". A disciplina aumenta as forças do corpo (em termos econômicos de utilidade) e diminui essas mesmas forças (em termos políticos de obediência). Em uma palavra: ela dissocia o poder do corpo; faz dele por um lado uma "aptidão", uma "capacidade" que ela procura aumentar; e inverte por outro lado a energia, a potência que poderia resultar disso, e faz dela uma relação de sujeição estrita. (FOUCAULT, 1987, p. 119).
\end{abstract}

Um aspecto importante da análise de Foucault consiste na ideia de que o poder disciplinar, embora encontre sua radicalização nos ambientes carcerários, perpassa toda a nossa sociedade. Encontramos técnicas disciplinares em instituições militares, hospitais, colégios e fábricas. O poder disciplinar possui alguns mecanismos eficientes: o olhar hierárquico e a sanção normalizadora.

O olhar hierárquico consiste em uma técnica de vigilância induzindo efeitos de poder específicos que funcionam como uma máquina de organização piramidal. Cada "olho" possui sua posição hierárquica e sua responsabilidade de vigilância. É verdade que pode existir um "chefe", mas para Foucault todo o aparelho produz poder, de modo que até mesmo aqueles que são encarregados de controlar estão sujeitos aos mecanismos de controle, de modo que o sistema se autossustenta por seus próprios mecanismos.

A sanção normalizadora, contudo, diz respeito ao mecanismo disciplinar que nos parece mais importante. Segundo Foucault, na essência de todos os sistemas disciplinares encontramos micropenalidades que tornam penalizáveis as infrações mais tênues da conduta. Encontramos inclusive um âmbito de infrapenalidades que preenchem os espaços vazios da lei e reprimem uma série de comportamentos não codificados. Qualquer desvio é passível de punição.

$\mathrm{Na}$ oficina, na escola, no exército funciona como repressora toda uma micropenalidade do tempo (atrasos, ausências, interrupções das tarefas), da atividade (desatenção, negligência, falta de zelo), da maneira de ser (grosseria, desobediência), dos discursos (tagarelice, insolência), do corpo (atitudes "incorretas", gestos não conformes, sujeira), da sexualidade (imodéstia, indecência). Ao mesmo tempo é utilizada, a título de punição, toda uma série de processos sutis, que vão do castigo físico leve a privações ligeiras e a pequenas humilhações. Trata-se ao mesmo tempo de tornar penalizáveis as frações mais tênues da conduta, e de dar uma função punitiva aos elementos aparentemente indiferentes do aparelho disciplinar: levando ao extremo, que tudo possa servir para punir a mínima coisa; que cada indivíduo se encontre preso numa universalidade punível-punidora. (FOUCAULT, 1987, p. 149).

É nesse contexto que o conceito de normalização, objetivo último da sanção normalizadora, é bastante relevante. Seu principal instrumento, a norma, é bastante diferente da lei jurídica. Para estarmos dentro da lei, precisamos não fazer tudo aquilo que ela proíbe. 
Isso nos deixa uma série de espaços de manobra, todo o resto é permitido. A norma, por sua vez, incita o indivíduo a uma adequação àquilo que deve ser feito. Na normalidade, tudo aquilo que se desvia da conduta ideal é suspeito. As micropenalidades da sanção normalizadora garantem que nossas crenças, desejos e comportamentos sejam organizados em direção à satisfação dos anseios de normalidade presentes em um dispositivo disciplinar.

Em nosso cotidiano vemos inúmeros exemplos de como as demandas de normalidade influenciam os comportamentos da sociedade, sem que seja necessário legislar acerca de tais comportamentos. O modo como nos vestimos, cortamos nossos cabelos, falamos, compartilhamos ideias, comemos e buscamos elementos culturais que formem nossa personalidade não possui legislações específicas, mas seria inocência dizer que todas as nossas escolhas são autônomas nestes âmbitos. De maneira consciente ou inconsciente, tentamos nos adequar aos padrões de normalidade existentes em nossa sociedade. Podemos, ainda, direcionar parte da nossa personalidade em um sentido subversivo que busque abalar tais padrões de normalidade (por algum motivo que nos pareça importante), mas, ainda assim, estamos nos remetendo a eles, com a diferença de que agora reagimos negativamente.

O modelo de vigilância presente na normalização disciplinar é análogo, segundo Foucault, ao Panóptico de Bentham. Uma construção em anel com uma torre no centro que possui a função de vigiar as salas que se encontram na periferia. Coloca-se um vigia no centro e aqueles que precisam ser vigiados nas celas. É importante que o vigia consiga ver todo mundo e ninguém consiga vê-lo. Nesse modelo, não é sequer necessário que o vigia esteja presente o tempo todo. Saber que você pode estar sendo vigiado é mais importante do que estar sendo vigiado. "Em uma sociedade disciplinar, todo mundo é em algum grau um juiz da normalidade. Estamos sendo potencialmente vigiados o tempo todo, em estado consciente e permanente de visibilidade" (FOUCAULT, 1987, p. 166), à mercê de infra-penalidades que são muitas vezes inconscientes. O dispositivo disciplinar é muito mais eficiente e muito menos violento do que o dispositivo de soberania. Bentham se maravilha com a leveza das instituições panópticas. Segundo Foucault: “O panoptismo é o princípio geral de uma nova 'anatomia política' cujo objeto e fimm não são a relação de soberania mas as relações de disciplina.” (1987, p. 172). Nesse contexto, a institucionalização generalizada da prisão como forma ideal de punição não é uma surpresa:

Acaso devemos nos admirar que a prisão celular, com suas cronologias marcadas, seu trabalho obrigatório, suas instâncias de vigilância e de notação, com seus mestres de normalidade, que retomam e multiplicam as funções do juiz, se tenha 
Artigo: Soberania, disciplina e segurança: uma análise do dispositivo e suas possíveis vertentes em Michel Foucault

tornado o instrumento moderno da penalidade? Devemos ainda nos admirar que a prisão se pareça com as fábricas, com as escolas, com os quartéis, com os hospitais, e todos se pareçam com as prisões? (FOUCAULT, 1987, p. 187).

Em termos de ressocialização dos indivíduos e prevenção dos crimes, a prisão fracassou completamente. As taxas de criminalidade não diminuem e a reincidência é uma constante. Mas para Foucault isso não consiste em um fracasso genuíno, pois esse nunca foi o real objetivo. O poder não se sustentaria se fosse completamente cínico. Ressocialização e prevenção são apenas discursos que legitimam o funcionamento do poder. O real objetivo das prisões reside na diferenciação das ilegalidades em que o crime deixa de ser uma virtualidade presente no coração dos condenados e passa a ser quase uma exclusividade de certa classe social. Seria "hipocrisia ou ingenuidade acreditar que a lei é feita para todo mundo em nome de todo mundo" (FOUCAULT, 1987, p. 229). A lei se aplica a todos apenas em princípio, na prática a vemos sendo formulada sempre por uma classe social e sendo aplicada a outra. Não é por acaso que vemos as prisões de nosso país repletas de pessoas pobres aguardando julgamentos e uma ínfima taxa de políticos comprovadamente corruptos sendo efetivamente condenados. Nos tribunais, temos uma classe fadada à ordem e outra à desordem.

É nesse contexto de diferenciação das ilegalidades que surge o grande triunfo da prisão como principal medida punitiva do dispositivo disciplinar: o surgimento da delinquência. Segundo Foucault, nesse modelo o infrator é substituído pelo delinquente. A administração abusa frequentemente de seu poder arbitrário, provocando um enorme sentimento de injustiça nos prisioneiros, tornando seus caráteres indomáveis. Expostos a sofrimentos que não foram previstos por lei, eles entram em um estado de cólera que os permite ver apenas carrascos nos agentes de autoridade. Ao sair da prisão, encontram-se praticamente impossibilitados de conseguir trabalho, tendo a reincidência como uma das únicas opções. A prisão estigmatiza o prisioneiro. Foucault não vê isso como um efeito colateral, mas como um de seus principais objetivos.

A Gazette des tribunaux, mas também os jornais operários citam muitas vezes casos
semelhantes, como o daquele operário condenado por roubo, posto sob vigilância
em Rouen, preso novamente por roubo, e que os advogados desistiram de defender;
ele mesmo toma então a palavra diante do tribunal, faz o histórico de sua vida,
explica como, saído da prisão e com determinação de residência, não consegue
recuperar seu ofício de dourador, sendo recusado em toda parte por sua qualidade de
presidiário; a polícia recusa-lhe o direito de procurar trabalho em outro lugar; ele se
viu preso a Rouen e fadado a morrer aí de fome e miséria como efeito dessa
vigilância opressiva. Pediu trabalho à prefeitura; ficou ocupado 8 dias nos cemitérios
por 14 soldos por dia: Mas, diz ele, sou moço, tenho bom apetite, eu comia mais de
duas libras de pão a 5 soldos a libra; que fazer com 14 soldos para me alimentar, 
lavar roupa e morar? Estava reduzido ao desespero, queria voltar a ser um homem honesto; a vigilância me fez mergulhar de novo na desgraça. Desgostei-me de tudo; foi então que conheci Lemaître que também está na miséria; tínhamos que viver e a má ideia de roubar nos voltou. - Enfim a prisão fabrica indiretamente delinquentes, ao fazer cair na miséria a família do detento. (FOUCAULT, 1987, p. 223).

A prisão cria uma sociedade de delinquentes. Não se trata de um fracasso do dispositivo, mas de um elemento necessário para manter o poder da classe dominante. Em $A$ prisão vista por um filósofo francês (1975), Foucault detecta dois elementos importantes para essa manutenção de poder: a desqualificação dos atos ilegais e a criminalidade como álibi contínuo da classe dominante.

Acerca da desqualificação dos atos ilegais, primeira função que justifica a existência dos delinquentes, Foucault alega que o objetivo principal é colocar os criminosos em condição de infâmia moral, de modo que essa classificação atinja, de modo geral, apenas uma parcela da população. Vamos explicar esse elemento com exemplos. Tomemos a exploração sexual. São instaurados mecanismos sociais de repressão social de modo que o sexo se torne uma mercadoria a ser explorada. Podemos fazer isso com o álcool, algumas drogas, o tabaco e as armas. A lógica é proibir, criar a necessidade e colocar na infâmia aqueles que fazem parte da classe dominada. As drogas não são proibidas visando a saúde das pessoas, a proibição das armas não tem o intuito de diminuir a criminalidade, tampouco o sexo é estigmatizado em benefício dos indivíduos ${ }^{2}$. Os exemplos poderiam ser outros, mas o fato é que nas sociedades em que funcionam os dispositivos disciplinares, sempre encontramos punições bastante contestáveis, aplicáveis apenas a uma parcela da população. A enorme dificuldade de colocar alguém de grande poder aquisitivo na prisão não é por acaso, e é tanto maior quanto mais carcerária e disciplinar for a sociedade em questão.

A segunda função dos delinquentes, a de álibi contínuo da classe dominante, consiste na fabricação do medo. Segundo Foucault (2010a, p. 157): “a delinquência dá medo, e se cultiva esse medo. Não é a troco de nada que, a cada momento de crise social e econômica, assiste-se a uma "recrudescência da criminalidade" e ao apelo consecutivo a um governo policial.". Esse medo é utilizado com o objetivo de legitimar, justificar e endurecer o controle social. O delinquente vira um inimigo externo que nos faz amar o poder policial, da mesma forma que o medo do inimigo externo nos faz amar o exército. Aquilo de que temos medo não é necessariamente aquilo que mais nos ameaça. A despeito dos altíssimos índices de mortes

\footnotetext{
${ }^{2}$ Importante ressaltar que isso funciona independentemente de a proibição das drogas tere algum efeito positivo sobre a saúde das pessoas, o desarmamento ter algum efeito positivo na diminuição de criminalidade e a repressão sexual ter alguma eficácia na saúde mental dos indivíduos.
} 
Artigo: Soberania, disciplina e segurança: uma análise do dispositivo e suas possíveis vertentes em Michel Foucault

no trânsito, podemos nos convencer de que precisamos ter mais medo de alguém pelo simples fato de esta pessoa ser usuário de alguma droga que se tornou ilegal. Não nos são fornecidas pesquisas científicas sérias acerca dos reais perigos que nos assolam e das maneiras mais eficientes para resolvê-los. Ao invés disso, somos encorajados a acreditar cada vez mais nas instituições ineficientes que foram encarregadas de nos proteger. Quanto mais ineficientes seus mecanismos, mais pedimos por um aumento de rigor, como se não restasse nenhuma alternativa possível além da submissão a uma classe detentora do monopólio da virtude e do poder de nos livrar daquilo que nos assola.

Dessa forma, o dispositivo disciplinar nos torna juízes da normalidade, como já visto. Segundo Foucault (1987, p. 251): “estamos na sociedade do professor-juiz, do médico-juiz, do educador-juiz, do 'assistente social' juiz; todos fazem reinar a universalidade do normativo". É verdade que aquilo que é considerado normal pode variar amplamente em cada sociedade, ou até mesmo dentro da mesma sociedade. Mas a normalidade é sempre uma meta a ser atingida. A efetiva periculosidade de um indivíduo importa pouco diante do medo que temos de sua virtual delinquência. Nós nos tornamos juízes que se importam pouco com os fatos empíricos e demasiadamente com nossos anseios de normalidade. A vigilância e a punição são sempre reservadas a uma classe específica fadada à desordem. Todos os atos destes são automaticamente criminalizáveis. A classe fadada à ordem, por sua vez, sempre possui um álibi. Nunca são anormais, apenas excêntricos. Suas naturezas violentas residem em alguma doença que pode e deve ser urgentemente tratada. A ineficiência da prisão é facilmente reconhecida quando algum representante óbvio da classe dominante se encontra questionado.

\section{DISPOSITIVO DE SEGURANÇA}

Para entendermos melhor em que consiste o dispositivo de segurança, precisamos de uma breve introdução acerca do conceito de biopolítica, encontrado no quinto capítulo de $A$ vontade de saber, e explicado a partir de seu contraste evidente com o poder soberano. No poder soberano o seu possuidor tinha um direito indireto e direto sobre a vida dos indivíduos, pois poderia ordenar que seus súditos defendessem o Estado em casos de guerra e condenar à morte aqueles que infringiam suas leis.

A partir da época clássica, o Ocidente sofre uma profunda modificação em seus mecanismos de poder. A morte deixa de ser um direito do soberano e passa a ser um direito 
do corpo social de manter sua própria vida. Nesse contexto, Foucault (1988, p. 128) observa um aspecto paradoxal: "jamais as guerras foram tão sangrentas como a partir do século XIX". Como pode um poder responsável pela vida ter como consequência tantas mortes? "As guerras já não se travam em nome do soberano a ser defendido; travam-se em nome da existência de todos; populações inteiras são levadas à destruição mútua em nome da necessidade de viver." (FOUCAULT, 1988, p. 129).

A existência da soberania não está mais em questão, e sim a existência biológica de toda uma população. A ideia de que é necessário matar para sobreviver passa a ser usada de maneira estratégica entre os Estados (tendo sua radicalização no nazismo). De acordo com Foucault: "Pode-se dizer que o velho direito de causar a morte ou deixar viver foi substituído por um poder de causar a vida ou devolver à morte.” (FOUCAULT, 1988, p. 130). Isso significa que agora a função do poder não consiste mais em buscar sua legitimidade na soberania para dispor do direito de matar os indivíduos, mas de aceitar o consenso de que a legitimidade do poder reside em sua capacidade de manter a vida biológica de sua população. A pena de morte passa a ser menos aceitável (precisando evocar a enormidade do crime e a monstruosidade do criminoso, algo desnecessário no poder soberano), o suicídio e a eutanásia passam a ser muito mais problemáticos.

Esse poder que surgiu no século XVII assume duas formas principais. A sua forma disciplinar, centrada no corpo-máquina e no adestramento dos indivíduos, já analisada aqui; e a sua forma biopolítica, centrada no corpo espécie e na gestão dos processos biológicos de uma população. Nesse contexto, surge uma série de intervenções, como índices de natalidade, mortalidade, saúde e longevidade, que juntas compõem aquilo que o autor denomina de uma biopolítica da população. Podemos chamar de biopoder essa união do poder disciplinar com a biopolítica, bastante presente em nossas sociedades contemporâneas. Não se proliferam apenas as instituições disciplinares como as fábricas, escolas e prisões, mas também as instituições biopolíticas voltadas à regulação da população, como o controle de natalidade e mortalidade, a demografia e a tabulação das riquezas.

Segundo Foucault, a lei precisa estar sempre armada, e seu último recurso é a morte. Todavia, se a lógica jurídico-discursiva presente no poder soberano encontra poucos obstáculos para dispor da morte, a lógica da norma presente no poder disciplinar e na biopolítica precisa de mecanismos mais contínuos e corretivos. Um poder cuja função principal é a manutenção da vida deve dispor mais de mecanismos que o permitam avaliar, qualificar e hierarquizar do que se manifestar em seu poder mortífero. A própria lei passa a 
Artigo: Soberania, disciplina e segurança: uma análise do dispositivo e suas possíveis vertentes em Michel Foucault

funcionar cada vez mais como norma. Isso não significa que a lei tenda a desaparecer, e sim que ela passa a se integrar cada vez mais com aparelhos de função reguladora, como as instituições medicinais, pedagógicas e administrativas.

A normalização não desaparece com a biopolítica. Pelo contrário, ela se fortalece ainda mais. Se no poder disciplinar temos uma normalização focada no indivíduo, na biopolítica temos uma normalização da população. Esse processo cria uma chantagem implícita aos indivíduos. Aquele que não se normalizar representa um risco a toda a população. Inúmeras pesquisas cientificamente duvidosas (mas com forte poder político) irão confirmar que os indivíduos "anormais" e "degenerados" representam um risco a toda a população e devem ser combatidos, não mais em nome do soberano, mas da vida biológica de uma população que, para se manter viva, precisa exterminar todos os perigos.

Segundo Leon Farhi Neto (2010), em sua obra intitulada Biopolíticas em Foucault, entre os anos de 1974 e 1979 Foucault investiga a biopolítica em sua relação com cinco temáticas principais: saúde, guerra, sexualidade, segurança e economia. Aqui iremos nos concentrar na questão da segurança para explicar em que consiste esse dispositivo derivado dela, que representa uma forte ferramenta diagnóstico sobre nossas relações de poder vigentes.

Foucault analisa o dispositivo de segurança em seu curso ministrado no Collège de France, intitulado Segurança, território, população. Para entendermos em que consiste o dispositivo de segurança, podemos compará-lo com os dispositivos anteriores, no contexto de resolução das questões político/sociais que nos colocam em situações inseguras. De acordo com a solução arcaica presente no dispositivo de soberania, cria-se uma lei que estabelece uma punição aos seus infratores. Segundo a solução moderna presente no dispositivo disciplinar, a solução reside em mecanismos de vigilância e correção. A solução contemporânea, por sua vez, presente no dispositivo de segurança, consiste na inserção de diversos fenômenos como o roubo, o assassinato e o estupro, em uma série de acontecimentos prováveis, que permitem um cálculo referente ao custo econômico, político e social das possíveis intervenções, visando à concretização de uma média considerada ótima. A intervenção é desejável apenas quando os custos forem menores do que os danos causados pelos fenômenos em questão.

Essa média considerada ótima assume literalmente uma análise estatística de custos e benefícios. Imagine que, em um contexto violento hipotético, seja possível reduzir $40 \%$ da violência com um investimento $\mathrm{X}$ de dinheiro, sem precisar diminuir drasticamente a 
liberdade dos indivíduos, aumentando pouco a repressão. Agora vamos supor que para diminuir mais $10 \%$ os custos sejam muito maiores, como por exemplo $2 \mathrm{X}$. A liberdade também precisaria ser consideravelmente reduzida, de modo que valha mais a pena conviver com essa parcela de violência do que buscar a ordem a todo custo. De certa forma, podemos dizer que buscar a perfeição de um sistema torna-o ineficiente, mas buscar a média ótima, a melhor relação de custo-benefício, pode ser uma meta desejável.

É importante ressaltar que o dispositivo de segurança não substitui o dispositivo de soberania e o dispositivo disciplinar. Um grande conjunto de medidas legislativas e técnicas disciplinares são necessários para fazer o dispositivo de segurança funcionar. Na Idade Média, por exemplo, o código legal referente ao roubo era muito mais simples do que hoje em dia em que temos não apenas leis acerca do roubo, mas do roubo cometido pelas crianças, doentes mentais etc. Para fazer mecanismos de segurança funcionarem é preciso inflacionar os dispositivos anteriores. O poder em nossas sociedades contemporâneas torna-se cada vez mais complexo. Nas palavras do autor: "A segurança é uma certa maneira de acrescentar, de fazer funcionar, além dos mecanismos propriamente de segurança, as velhas estruturas da lei e da disciplina." (FOUCAULT, 2008, p. 14).

Foucault alega que antigamente a relação entre um povo e seu governo se dava através de um "pacto territorial" em que o Estado dizia "vou lhes dar um território", ou "vocês viverão em paz em suas fronteiras". A relação era muito mais baseada no território do que nas obrigações do Estado para com seus súditos. Atualmente, todavia, estamos inseridos em um "pacto de segurança", entendido da seguinte maneira:

O que o Estado propõe como pacto com a população é: "Vocês estarão seguros". Garantidos contra tudo o que pode ser incerteza, acidente, prejuízo, risco. Vocês estão doentes? Terão a seguridade social! Não têm trabalho? Terão um segurodesemprego! Há um vagalhão? Criaremos um fundo de solidariedade! Há delinquentes? Vamos assegurar-lhes a sua correção, uma boa vigilância policial. (FOUCAULT, 2010b, p. 172).

A partir desse pacto de segurança, torna-se legítimo que o Estado venha a intervir sempre que a vida cotidiana se encontre ameaçada por algum acontecimento excepcional. A lei pode muito bem não estar adaptada para lidar com algum acontecimento imprevisível. Nesse contexto, Foucault alega que as intervenções não serão entendidas "como signo do arbitrário nem de excesso de poder, mas, ao contrário, de uma solicitude" (FOUCAULT, 2010b, p. 173). Foucault chama isso de "solicitude onipresente" do Estado. Nesse contexto, o 
Artigo: Soberania, disciplina e segurança: uma análise do dispositivo e suas possíveis vertentes em Michel Foucault

terrorismo é a grande ameaça que coloca em perigo o pacto de segurança, provocando enorme angústia nos governantes que precisam dele para garantir sua legitimidade e nos governados que aceitaram inúmeros impostos, divisões hierárquicas e obrigações de obediência, em troca de uma segurança que encontra-se agora ameaçada.

Se em Vigiar e punir Foucault chamou nossas sociedades de "sociedades disciplinares", agora lhes dá a alcunha de "sociedades de segurança". As sociedades de segurança, para o autor, toleram uma maior variedade de comportamentos diferentes, desviantes e antagônicos. É verdade que existe a condição de que esses comportamentos "se achem em um certo envelope que eliminará coisas, pessoas, comportamentos considerados acidentais e perigosos." (FOUCAULT, 2010b, p. 174). Mas também é verdade que possuímos agora uma margem de manobra e um pluralismo muito maior do que o encontrado nos totalitarismos. O desenvolvimento do Estado não se encontra em um enrijecimento cada vez maior, mas em uma flexibilidade bastante maleável. Os efeitos positivos e negativos dessa condição transcendem os objetivos de Foucault, muito mais interessado em compreender o funcionamento do poder atual em busca de um diagnóstico mais verossímil.

Todavia, não devemos nos enganar. Como já visto, o dispositivo de segurança que se legitima por uma certa "frugalidade" governamental pressupõe uma quantidade muito maior de medidas legislativas e disciplinares do que os modelos anteriores. Nesse contexto, surge o conceito de homo oeconomicus, que se apresenta como uma solução racional para a governamentalidade estatal. Sob a perspectiva governamental, não se governa mais indivíduos culturais com interesses e deveres diversos, mas uma série de processos que podem ser inseridos em uma estatística. Nesse contexto, cabe discernir a diferença que Foucault sugere acerca do "povo" e da "população". A população é entendida como este aglomerado de homo oeconomicus, entendidos como processos biológicos racionais a serem geridos. O "povo" é tudo aquilo que vai desajustar o sistema. Trata-se do conjunto de indivíduos que não podem ser governados dessa maneira, que não agem de maneira racional tampouco se sujeitam à lógica da governamentalidade pelo dispositivo de segurança. O "povo" não consegue se adequar às expectativas racionais do homo oeconomicus e por isso representa um obstáculo à racionalidade biopolítica.

Importante ressaltar que a distinção "povo" e "população", mesmo que não teorizada e inconsciente, serve para segregar os indivíduos ingovernáveis e absolver o governo de qualquer incompetência possível, pois sempre é possível frisar a ingovernabilidade do povo, deslegitimando seus direitos e necessidades. Sempre que existem dificuldades em governar 
uma população, é possível apelar para este subterfúgio que exime os governantes de qualquer responsabilidade.

\section{CONCLUSÃO}

Precisamos tomar certo cuidado ao ler e interpretar Foucault. Corremos o risco de ler muito mais o que está escrito, ou muito menos. Dessa forma, é importante ressalvar que suas análises possuem o objetivo de servirem como ferramentas aos intelectuais, profissionais, especialistas e leigos que busquem maior esclarecimento sobre os temas tratados. Foucault evita ser doutrinário e conduzir o leitor a uma conclusão específica, porém de maneira bastante consciente de que a neutralidade é uma quimera. Dito isso, não devemos ler os dispositivos analisados aqui como ferramentas de opressão a ser rejeitada a qualquer custo, tampouco como relações de poder inevitáveis às quais deveríamos nos render. O primeiro passo para termos uma relação autônoma com os dispositivos presentes em nossas sociedades é o diagnóstico, e este é o objetivo fundamental de Foucault.

Nunca seremos completamente livres, tampouco completamente sujeitados. Entender as relações de poder que nos circundam consiste em um primeiro passo em direção a autonomia que nos permitirá aceitá-las, modificá-las ou recusá-las completamente. Acreditamos que analisar nossas sociedades à luz de uma compreensão lúcida dos dispositivos transitórios que se encontram entre nós é uma tarefa bastante profícua. Mas não nos deixemos enganar. O poder funciona de maneira complexa e heterogênea. Todos os dispositivos analisados são relevantes, não podemos cair no erro de achar que um suplantou completamente o outro. Tampouco podemos nos dar ao luxo de cristalizar a leitura de Foucault, feita em um momento histórico específico, utilizando-se apenas de um recorte da realidade, mesmo que com bastante consciência disso.

\section{REFERÊNCIAS}

FARHI NETO, Leon. Biopolíticas. As formulações de Foucault. Florianópolis. Cidade Futura. 2010.

FOUCAULT, Michel. Microfísica do Poder. 11. ed. Tradução de Roberto Machado. Rio de Janeiro: Graal, 1979.

FOUCAULT, Michel. Sobre a história da sexualidade. In: FOUCAULT, Michel. Microfísica do poder. 11. ed. Rio de Janeiro: Graal, 1979, p. 243 - 276 
Artigo: Soberania, disciplina e segurança: uma análise do dispositivo e suas possíveis vertentes em Michel Foucault

FOUCAULT, Michel. Vigiar e punir: história da violência nas prisões. 32. ed. Tradução de Raquel Ramalhete. Petrópolis: Vozes, 1987.

FOUCAULT, Michel. História da Sexualidade 1: a vontade de Saber. 11. ed. Tradução de Maria Thereza da Costa Albuquerque e J.A. Guilhon Albuquerque. Rio de Janeiro: Graal, 1988.

FOUCAULT, Michel. Ética, sexualidade, política: ditos e escritos. Vol. V, 2. ed. Tradução de Elisa Monteiro e Inês Autran Dourado Barbosa. Rio de Janeiro: Forense Universitária, 2006.

FOUCAULT, Michel. Segurança, Território, População. Curso no Collège de France (1977-1978). Tradução de Eduardo Brandão. São Paulo: Martins Fontes, 2008.

FOUCAULT, Michel. Estratégia, poder-saber: ditos e escritos. 2. ed. Vol. IV. Tradução de Vera Lucia Avellar Ribeiro. Rio de Janeiro: Forense Universitária, 2010a.

FOUCAULT, Michel. Repensar a política: ditos e escritos. Vol. VI. Tradução de Ana Lúcia Paranhos Pessoa. Rio de Janeiro: Forense Universitária, 2010b.

OKSALA, Johanna. Foucault on Freedom. New York: Cambridge University Press, 2005.

REVEL, Judith. Dicionario Foucault. São Paulo: Forense universitária, 2011.

VEYNE, Paul. Como se escreve a história: Foucault revoluciona a história. Brasília: UnB, 2014. 